\title{
Established Diagnosis
}

National Cancer Institute

\section{Source}

National Cancer Institute. Established Diagnosis. NCI Thesaurus. Code C50839.

The identification of a disease by its signs, symptoms and results of various diagnostic procedures. The final conclusion reached through this process is called an established diagnosis. 